\title{
Exploring the Factors Associated with Car Use for Short Trips: Evidence from Kunming, China
}

\author{
Mingwei He $(\mathbb{D}$, Yi Fei $(\mathbb{D}$, and Min He $\mathbb{i}$ \\ Faculty of Transportation Engineering, Kunming University of Science \& Technology, Jingming Road 727, \\ Kunming 650500, China \\ Correspondence should be addressed to Mingwei He; hmwei01@163.com
}

Received 8 October 2019; Revised 7 December 2019; Accepted 26 December 2019; Published 1 February 2020

Academic Editor: Jaeyoung Lee

Copyright (c) 2020 Mingwei He et al. This is an open access article distributed under the Creative Commons Attribution License, which permits unrestricted use, distribution, and reproduction in any medium, provided the original work is properly cited.

The purpose of this study is to explore the factors associated with car use for short trips. Using the data collected from a travel survey conducted with car users in Kunming, the structural equation model is employed to explore the structural relationships between car use for short trips, attitudes toward cars and alternative travel modes, sociodemographics, and the built environment. The results show that instrumental and symbolic attitudes toward cars are positively related to the affective attitude, and these three attitudes have a significant effect on car use for short trips. The symbolic attitude of drivers is negatively associated with their walking and cycling attitudes. Drivers with a better cycling attitude use a car less frequently for short trips. Concurrently, the effects of sociodemographics and the built environment on the attitudes and car use for short trips are also identified. The findings may contribute to understanding the car use behavior and help policy makers to identify methods for reducing car use more clearly.

\section{Introduction}

In recent decades, with the rapid economic development and urbanization in China, cars are being increasingly used by families. Statistics from the National Bureau of Statistics of China in 2018 show that the number of private cars has reached 20.6 million [1]. Cars have gradually become an important travel mode in urban residents' daily life. Increased car use brought a series of negative problems, such as traffic congestion and air pollution, which have put tremendous pressure on energy crisis and climate change.

There is a general consensus that we need to reduce car trips to minimize these negative impacts [2]. Although it should be admitted that car use is necessary in response to some certain needs, unnecessary usage of cars must be reduced, particularly for some short trips. In fact, a majority of our daily trips by cars are proved to be short [3]. A study in Sydney showed that nearly a quarter of the car trips were less than $5 \mathrm{~min}$ in duration [4]. According to the fourth Comprehensive Traffic Survey in Beijing in 2010, car trip distances of less than $5 \mathrm{~km}$ accounted for more than $40 \%$ of the total number of car trips [5]. Short-distance car trips may require more fuel and generate more harmful emissions, such as carbon monoxide (CO), because they are always driven in urban areas with cold engines, compared with long-distance trips $[6,7]$. Unlike long-distance trips, short trips in a car can be more easily replaced by other travel modes, such as walking and cycling. This is more likely to reduce car use for short trips. Moreover, promoting drivers to substitute car use with active travel modes also benefits public health and contributes to a low-carbon society [8].

Existing studies have analyzed the determinants of car use from different perspectives. These include sociodemographics of the traveler $[9,10]$, attitudes and perceptions toward cars $[11,12]$, built environment $[13,14]$, and the instrumental function of the car itself [15-17]. However, only a few studies have focused on car use for short trips. A Dutch study [6] investigated short car trips from a long-term travel survey of 35 car drivers. The results attributed the usage of cars for short trips to the transport of heavy goods and passengers. Another study [18] showed that the convenience of parking a car induced the park and ride demand, 
and weather influenced the decisions of drivers to use cars for short trips. Additional influencing factors such as the individual and household socioeconomic status of the traveler, availability of cars and alternative modes, trip purpose, and the built environment of their residence also play an essential role in choosing the mode for short trips $[19,20]$.

Overall, the influencing mechanism of car use for short trips is not well understood, and several issues need to be further explored. First, the attitudes of travelers toward cars play an important role in explaining car use. Although the existing studies have investigated the instrumental, affective, and symbolic attitudes toward cars and their effects on car use [21-23], it is necessary to verify the effects of these attitudes on car use for short trips further. Second, besides the attitudes of car users toward their cars, we should also pay attention to their attitudes toward alternative travel modes. This may help to understand the reasons they select cars instead of alternative modes. Third, the effects of sociodemographics and the built environment on car use for short trips require further exploration. Examining these issues will contribute to a more comprehensive understanding of car use for short trips. In this study, using data collected from a travel survey conducted with car users in Kunming, the structural equation model (SEM) is employed to explore the structural relationships between the car use for short trips, attitudes toward different travel modes, sociodemographics, and the built environment.

The remainder of this article is structured as follows. The next section introduces the conceptual model. Section 3 presents the data collection, key variables, and method. Section 4 discusses the model results. Our conclusions are presented in the final section.

\section{Conceptual Model}

Existing studies have generally proven that attitudes have a significant impact on car use. Attitudes toward cars mainly consist of three components: instrumental aspect, symbolic aspect, and affective aspect [22-24]. The instrumental function of the car leads people to prefer using cars than other travel modes because they move faster and are always available for the trips [25]. Symbolic function could display drivers' social identity and express their self-concept to some extent [23]. Affective function refers to drivers' emotional feelings, such as the pleasure of driving and the passion for speed $[12,24]$. In exploring the relationship among instrumental function, symbolic function, and affective function of the car, Steg and Tertoolen [21] proposed a theoretical model that car use depended on social, affective, and instrumental motivations; meanwhile, instrumental and symbolic motivations have an effect on affective motivation. Steg and his colleagues further verified this model empirically [22, 23]. Gatersleben [26] also reported that affective function of a car depended on its instrumental function and symbolic function.

The initial conceptual model structure of the interrelationships is presented in Figure 1. According to the theoretical model proposed by Steg and Tertoolen [21], the model assumed that car use depended on instrumental, symbolic, and affective attitudes, and the affective attitude was a consequence of the instrumental and symbolic attitude. These three attitudes affect car use in the meanwhile.

Considering that walking and cycling are the main alternatives to cars for short trips, we also included the impact of drivers' attitudes toward walking and cycling. In our hypothesis, walking and cycling attitudes directly influence car use for short trips, and the awareness of drivers about the environmental problems is considered to affect the car use, walking, and cycling attitudes. Besides the interrelationships between the three attitudes toward cars, the walking and cycling attitudes of car users are also verified. In the model, these attitudes are included as latent variables, which are measured by a series of attitude indicators. All these attitudes and car use for short trips are assumed to be influenced by sociodemographics and the built environment.

\section{Research Design}

3.1. Data Collection. The data for this study were obtained through a short-distance travel survey conducted in May 2019 in Kunming. Kunming is the capital of the Yunnan province in southwest China. Kunming is a representative of numerous Chinese cities with a hierarchical center structure and comparative size. The urban region of Kunming, which consists of the five districts: Chenggong, Wuhua, Panlong, Xishan, and Guandu, is shown in Figure 2. Approximately 3.6 million individuals live in the urban area of Kunming, the population density in 2018 was 10902 inhabitants $/ \mathrm{km}^{2}$.

Given the objectives of the study, we only selected respondents who are car users. The questionnaire included questions about their sociodemographic characteristics, driving information, attitudes, perceptions toward different travel modes, and information about their last 5 short trips (less than $4 \mathrm{~km}$ ). The respondents were approached at multiple automobile $4 \mathrm{~S}$ shops, garages, and public parking lots located in the five districts. All the respondents were given a reward of $10 \mathrm{CNY}$. In each district, we planned to obtain approximately 70 random samples. A total of $341 \mathrm{car}$ users completed the questionnaires, and 26 questionnaires were eliminated owing to incomplete responses. Overall, the database used for this study included 315 valid samples. In general, the survey captured various car users in Kunming, and the sample was representative of the car users with respect to gender, age, household income, and employment status. A description of the sample is provided in Table 1.

3.2. Key Variables. The variables used in the analysis include personal and household characteristics, built environment, attitudes, and car use for short trips. The definition of short trip varies between studies [7, 27-29]. Lee et al. defined $8 \mathrm{~km}$ as the maximum distance for a short round trip ( $4 \mathrm{~km}$ for a one-way trip) [7]. de Nazelle et al. used 3 miles $(4.8 \mathrm{~km})$ as the threshold value for a short trip [27]. According to the report of the 2016 Kunming Urban 


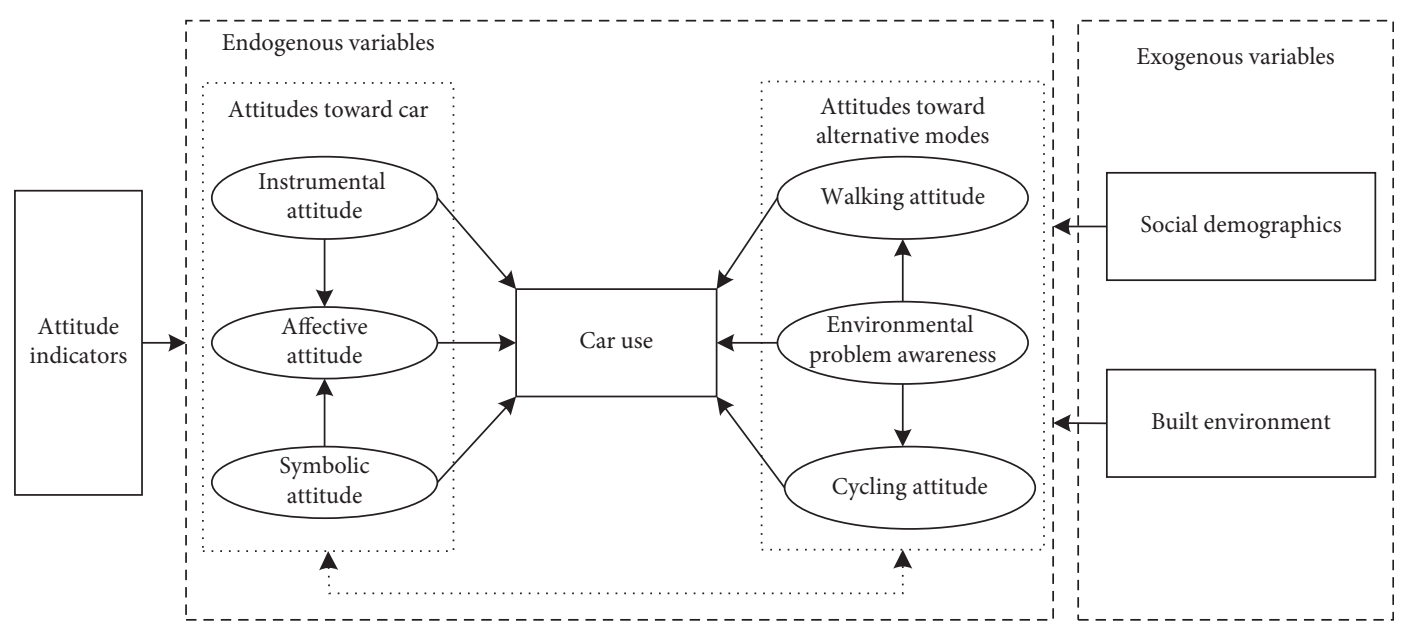

FIgure 1: Conceptual model structure.
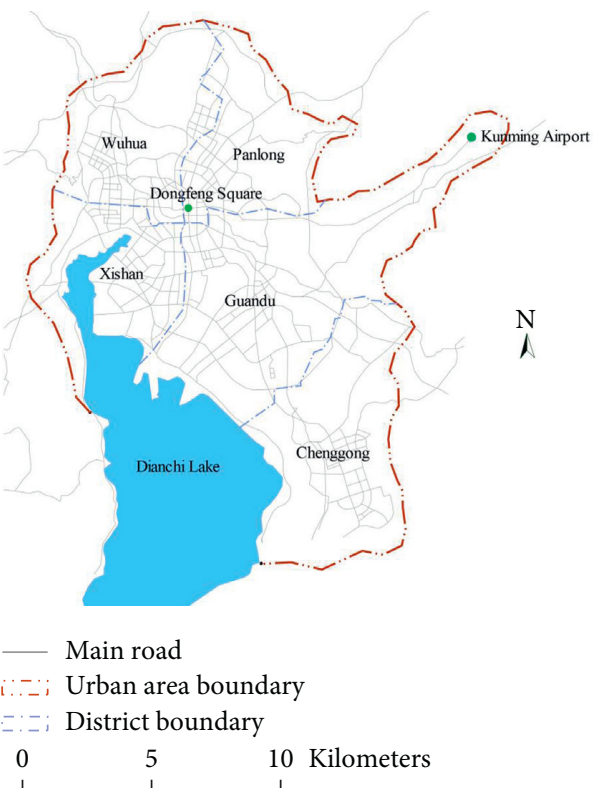

Figure 2: Map of the urban area of Kunming.

Residents Travel Survey [30], the average distance cycled is $2.9 \mathrm{~km}$, and $75.6 \%$ of all cycling trips are less than $4 \mathrm{~km}$. Almost all walking trips are within $4 \mathrm{~km}$. Considering walking and cycling are potential alternatives to short car trips, a short trip is defined as a one-way trip within $4 \mathrm{~km}$. Car use for short trips is an outcome variable. In our model, the percentage of trips made by a car in the past five short trips is the measure of car use. Consequently, the values range from 0 to 1 , and the mean is 0.49 .

The personal and household characteristics included gender, age, education level, employment status, driving experience, annual household income, and car ownership. Age is classified into three categories: 18-30, 31-50, and older than 50. Education level is classified into two categories: high school or less, and college or higher. Two categories are differentiated for employment status: staff and others, where staff mainly includes being an employee in an enterprise, a public institution staff or civil servant. The driving experience of a participant is classified into two categories: less than and greater than 10 years. The annual household income is divided into three categories: low (less than $100,000 \mathrm{CNY})$, medium (100,000-200,000 CNY), and high (more than 200,000 CNY). Two categories are differentiated for car ownership: households owning one car, and households owning two or more cars. Furthermore, the dominance of the car in a family, which may affect car use of a participant for short trips, is also considered. The dominance of a car in a family is classified into three categories: fully dominated by yourself, used more by yourself, and used more by your family members.

In this study, the built environment variables only include the number of bus stops around the residences of the respondents and the linear distance from their residence to the city center. Because the average pedestrian distance to bus stops is generally approximately $500 \mathrm{~m}$ [31, 32], we searched for the number of bus stops within a radius of $500 \mathrm{~m}$ from the residences of the participants. The average number of bus stops around their residences is 9.17, and the standard deviation is 4.60. Considering the overall layout of Kunming, this study adopted the Dongfeng Square (marked in Figure 1) as the city center. The average linear distance from respondents' residences to Dongfeng Square is $10.02 \mathrm{~km}$, and the standard deviation is 7.62 .

According to the theoretical model proposed by Steg and Tertoolen [21], the attitudes toward a car include instrumental, symbolic, and affective attitudes. In this study, these attitudes were the latent variables and measured by their indicators. The participants indicated the degree of agreement on a Likert scale ranging from 1 (totally disagree) to 7 (totally agree) for each statement. The statements were designed in accordance with the studies exploring how attitudes influence car use $[2,18,23,24]$ and with actual situations of the survey area.

The instrumental attitude is measured by five statements: "Using a car allows me to choose my own route," "Using a car can protect me against bad weather," "A car can make it easy to go out at any time," "A car can make it easy to reach 
TABle 1: Sample characteristics.

\begin{tabular}{|c|c|c|c|}
\hline Variables & Classification & Cases & Percentage (\%) \\
\hline \multirow{2}{*}{ Gender } & Male & 200 & 63.5 \\
\hline & Female & 115 & 36.5 \\
\hline \multirow{3}{*}{ Age } & $18-30$ & 156 & 49.5 \\
\hline & $31-50$ & 141 & 44.8 \\
\hline & $>50$ & 18 & 5.7 \\
\hline \multirow{2}{*}{ Education level } & High school or less & 63 & 20.0 \\
\hline & College or higher & 252 & 80.0 \\
\hline \multirow{3}{*}{ Employment status } & Staff & 210 & 66.7 \\
\hline & Others & 105 & 33.3 \\
\hline & $<100,000$ & 133 & 42.2 \\
\hline \multirow{2}{*}{ Annual household income (CNY) } & $100,000-200,000$ & 121 & 38.4 \\
\hline & $>200,000$ & 61 & 19.4 \\
\hline \multirow{2}{*}{ Car ownership } & 1 & 206 & 65.4 \\
\hline & $\geq 2$ & 109 & 34.6 \\
\hline \multirow{3}{*}{ Dominance of the car } & Fully dominated by yourself & 110 & 34.9 \\
\hline & Used more by yourself & 108 & 34.3 \\
\hline & Used more by your family & 97 & 30.8 \\
\hline \multirow{2}{*}{ Driving experience (years) } & $0-10$ & 258 & 81.9 \\
\hline & $>10$ & 57 & 18.1 \\
\hline
\end{tabular}

any place directly," and "A car can pick up passengers and carry capacity." The symbolic attitude is measured by four statements: "A car can distinguish me from the rest of people," "A car can express my taste and hobby," "A car can show my success to others," and "A car can make me more confident." The affective attitude is measured by four statements: "Driving can make me enthusiastic," "Driving is enjoyable," "I'm fond of my car," and "I feel everything is under control when I drive."

Considering that walking and cycling are the main alternatives to car use for short trips, we also investigated the attitudes of the participants toward walking and cycling. The Statements are "Cycling can benefit my health" and "Cycling is enjoyable" are designed for measuring the attitude toward cycling. Statements "Walking can benefit my health" and "Walking is enjoyable" are for measuring the attitude toward walking [33]. Moreover, the environmental problem awareness is measured using the following statements: "Car emission is an important cause of air pollution" [34] and "I think transportation has a huge impact on the environment, and I support low-carbon travel." Descriptive statistics of all the attitude statements are shown in Table 2.

3.3. Method. The structural equation model (SEM) has been widely used for exploring the travel behavior $[35,36]$. In this study, the SEM was employed to explore the structural relationships between the car use for short trips, attitudes toward different travel modes, sociodemographics, and the built environment. SEM was chosen for its ability to capture both the effects of exogenous variables on endogenous variables, and the effects of endogenous variables on each other [37].

The model was developed by using MPLUS Version7 software. In this study, the attitude indicators were collected on a seven-point Likert scale and were treated as categorical variables. The sociodemographic attributes were also grouped to be included in the model. Therefore, we used an available method named weighted least square parameter estimator (WLSMV), which is a robust estimator designed for processing categorical-dependent variables with robust standard errors and does not require a large sample size [38].

The final model was modified in two phases. First, based on the conceptual model, all the variables and relationships were included in the model. Second, based on the model output, except the direct links between the attitudes toward the travel modes and car use for short trips, we discarded the links when the direct effects were not significant.

\section{Results}

4.1. Model Fit Indices. Table 3 lists the model-fitted indices from several aspects. The $\chi^{2}$ statistic is used to measure the discrepancy between the model-based and observed covariance matrices. Because the $\chi^{2}$ statistic increases with the sample size, it is not considered as a good measure of the goodness of fit. To reduce the sensitivity of the $\chi^{2}$ statistic to the sample size, it can be divided by the degrees of freedom. The value of $\chi^{2} / \mathrm{d} f$ is 2.55 , which is lower than the cutoff value of 3.0; values of 3 or less indicate a good fit [36]. The comparative fit index (CFI) and Tucker-Lewis index (TLI) are used to evaluate he improvement of the hypothesized model compared with the independence model with unrelated variables [39]. The value of the CFI is 0.926 , and TLI is 0.917 , indicating that the model has an acceptable fit. The value of the root-mean-square error of approximation (RMSEA) is 0.070 , which exhibits a reasonable fit.

4.2. Measurement of Attitude Latent Variables. In the structural equation context, the measurement model specifies how the latent variables are measured by the observed variables. In our model, the attitude latent variables are measured by a series of attitudinal statements (mentioned in chapter 3.2.2). Table 4 lists the statements included in each 
Table 2: Descriptive statistics of the attitudes.

\begin{tabular}{lcccc}
\hline Attitudes & Number of statements & Mean & SD & Cronbach alpha \\
\hline Instrumental attitude & 5 & 5.75 & 1.28 & 0.82 \\
Symbolic attitude & 4 & 3.23 & 2.32 & 0.79 \\
Affective attitude & 4 & 4.41 & 1.81 & 0.82 \\
Cycling attitude & 2 & 5.41 & 1.44 & 0.71 \\
Walking attitude & 2 & 5.68 & 1.30 & 0.74 \\
Environmental awareness & 2 & 5.36 & 1.47 & 0.70 \\
\hline
\end{tabular}

TABle 3: Model fit result.

\begin{tabular}{lccccc}
\hline & $\chi^{2}(\mathrm{~d} f) p$ & $\chi^{2} / \mathrm{d} f$ & CFI & TLI & RMSEA \\
\hline Desired values & $p>0.05$ & $<3.0$ & $>0.9$ & $>0.9$ & $<0.08$ \\
Model-based values & $1022.825(165) 0.00$ & 2.55 & 0.926 & 0.917 & 0.070 \\
\hline
\end{tabular}

TABLE 4: The results of measurement model.

\begin{tabular}{|c|c|c|c|c|}
\hline Latent variables & Attitude statements & $\begin{array}{l}\text { Standardized factor } \\
\text { loading }\end{array}$ & S.E. & $\begin{array}{l}\text { Two-tailed } p \\
\text { value }\end{array}$ \\
\hline \multirow{5}{*}{$\begin{array}{l}\text { Instrumental attitude } \\
\text { towards car }\end{array}$} & Using the car allows me to choose my own route. & 0.772 & 0.029 & $<0.001$ \\
\hline & Using the car could protect me against bad weather. & 0.707 & 0.030 & $<0.001$ \\
\hline & The car could make me easy to go out at any time. & 0.868 & 0.021 & $<0.001$ \\
\hline & The car could make me easy to reach any place directly. & 0.713 & 0.029 & $<0.001$ \\
\hline & The car could pick up passengers and carry capacity. & 0.706 & 0.031 & $<0.001$ \\
\hline \multirow{4}{*}{$\begin{array}{l}\text { Symbolic attitude towards } \\
\text { car }\end{array}$} & The car can distinguish me from the rest of people. & 0.880 & 0.015 & $<0.001$ \\
\hline & The car could express my taste and hobby. & 0.869 & 0.016 & $<0.001$ \\
\hline & The car could show my success to others. & 0.916 & 0.012 & $<0.001$ \\
\hline & The car could make me more confident. & 0.923 & 0.012 & $<0.001$ \\
\hline \multirow{4}{*}{$\begin{array}{l}\text { Affective attitude towards } \\
\text { car }\end{array}$} & Driving could bring me enthusiasm. & 0.907 & 0.024 & $<0.001$ \\
\hline & Driving is enjoyable. & 0.714 & 0.029 & $<0.001$ \\
\hline & I'm fond of my car. & 0.534 & 0.038 & $<0.001$ \\
\hline & I feel everything under control when I drive. & 0.549 & 0.039 & $<0.001$ \\
\hline \multirow{2}{*}{ Attitude towards cycling } & Cycling could benefit my health. & 0.901 & 0.024 & $<0.001$ \\
\hline & Cycling is enjoyable. & 0.754 & 0.028 & $<0.001$ \\
\hline \multirow{2}{*}{ Attitude towards walking } & Walking could benefit my health. & 0.860 & 0.025 & $<0.001$ \\
\hline & Walking is enjoyable. & 0.895 & 0.024 & $<0.001$ \\
\hline \multirow{2}{*}{$\begin{array}{l}\text { Environmental problem } \\
\text { awareness }\end{array}$} & Car emission is an important reason for air pollution. & 0.714 & 0.034 & $<0.001$ \\
\hline & $\begin{array}{l}\text { I think transportation has a great impact on environment and I } \\
\text { support the low-carbon travel. }\end{array}$ & 0.583 & 0.038 & $<0.001$ \\
\hline
\end{tabular}

attitude latent variable and the standardized factor loadings for each statement. All the statements in the measurement model have standardized factor loadings larger than 0.5 , and all of them are significant at $p<0.001$.

\subsection{Structural Relationships and Effects between Endogenous} Variables. Figure 3 displays the relationships between the endogenous variables, along with the corresponding standardized weights. Both the instrumental and symbolic attitudes have statistically significant positive effects on the affective attitude. The magnitude of the effect on the affective attitude by the instrumental attitude is smaller than that by the symbolic attitude. The environmental problem awareness shows a significant positive impact on both the walking and cycling attitudes. Car users with a better environmental awareness have a higher evaluation of the benefits brought by walking and cycling. We also find significant negative effects of the symbolic attitude on walking and cycling attitudes. These results indicate that car users who care more about the symbolism of a car have a lower evaluation of walking and cycling.

The direct and indirect effects of the attitude variables on car use for short trips are listed in Table 5. The affective attitude has a significant positive direct effect on car use for short trips. The direct effect of the instrumental attitude is not statistically significant. However, the instrumental attitude has a significant indirect effect on car use for short trips based on the affective attitude. In terms of the symbolic attitude, it has a significant positive total indirect effect on 


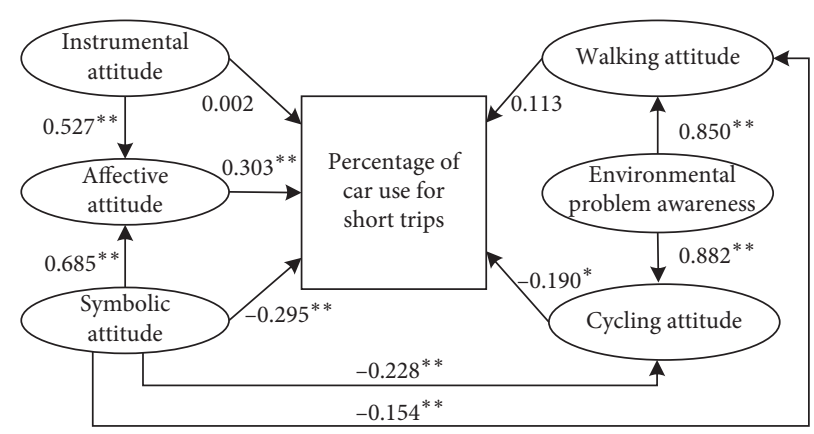

FIGURE 3: Structural relationships between the endogenous variables (note: ${ }^{*} p<0.1$ and ${ }^{* *} p<0.05$ ).

TABLE 5: Standardized direct, indirect, and total effects of the attitudes on car use.

\begin{tabular}{|c|c|c|c|}
\hline Attitudes & Direct effect & Indirect effect & Total effect \\
\hline Instrumental attitude & 0.002 & $0.160^{* *}$ & $0.162^{* *}$ \\
\hline Symbolic attitude & $-0.295^{* *}$ & $0.234^{* *}$ & $-0.061^{* *}$ \\
\hline Affective attitude & $0.303^{* *}$ & & $0.303^{* *}$ \\
\hline Cycling attitude & $-0.190^{*}$ & & $-0.190^{*}$ \\
\hline Walking attitude & 0.113 & & 0.113 \\
\hline Environmental problem awareness & & -0.06 & -0.06 \\
\hline
\end{tabular}

Note: ${ }^{*} p<0.1$ and ${ }^{* *} p<0.05$.

car use for short trips via three mediating variables. In detail, it has a significant positive indirect effect on car use for short trips via the affective attitude. Moreover, the symbolic attitude has a significant positive indirect effect on car use for short trips based on the cycling attitude and none through the walking attitude. Different from our expectations, the symbolic attitude has a negative direct and total effect on car use for short trips. In terms of the individual attitude toward the alternative modes, the cycling attitude has a negative effect on car use for short trips. This indicates that drivers with a better cycling attitude use a car less for short trips. However, the walking attitude is less related to car use for short trips.

4.4. Effects of the Exogenous Variables on Attitudes and Car Use. Table 6 lists the direct, indirect, and total effects of the exogenous variables on the attitudes and car use for short trips. The total effect is the sum of the direct and indirect effects. In terms of personal characteristics, age is negatively related to the affective attitude. It appears the affection of an individual for a car decreases with increasing age. Age also has a significant negative indirect effect on car use for short trips through the affective attitude. Gender has a significant positive direct effect on the affective attitude and positive indirect effect on car use for short trips. This indicates that men have a deeper affection for a car and are more likely to use cars for short trips when compared with women. The education level has a significant negative direct effect on the symbolic attitude and negative indirect effect on the affective attitude via the symbolic attitude. Simultaneously, car users with a college education are more are likely to have a higher evaluation of the benefits of walking and cycling when compared with those with a high school education or less. Nevertheless, the total effect of the education level on car use is not significant. Compared with others, staff is positively related to car use for short trips. The driving experience is positively related to the instrumental attitude and has a positive indirect effect on the affective attitude through the instrumental attitude. Although the indirect effect of the driving experience on car use for short trips is positive, the total effect is negative.

In terms of the household characteristics, compared with the reference group with an annual household income below $100,000 \mathrm{CNY}$, the group with an annual household income above 200,000 CNY has a significant positive direct effect on the symbolic attitude. It also has a significant positive indirect effect on the affective attitude and negative indirect effect on the cycling and walking attitudes through the symbolic attitude. Moreover, both the higher income groups have a significant negative direct effect on the cycling attitude. According to the total effect, people belonging to the group with an annual household income above 200,000 CNY are more likely to use a car for short trips. Car use is also positively related to the car ownership in a household and car dominance.

In terms of the built environment, people living in a residential area with more bus stops are less likely to use a car for short trips. The linear distance to the city center has a significant positive direct effect on the instrumental attitude and positive indirect effect on the affective attitude through the instrumental attitude. According to the total effect, car use is positively related to the linear distance to the city center. 


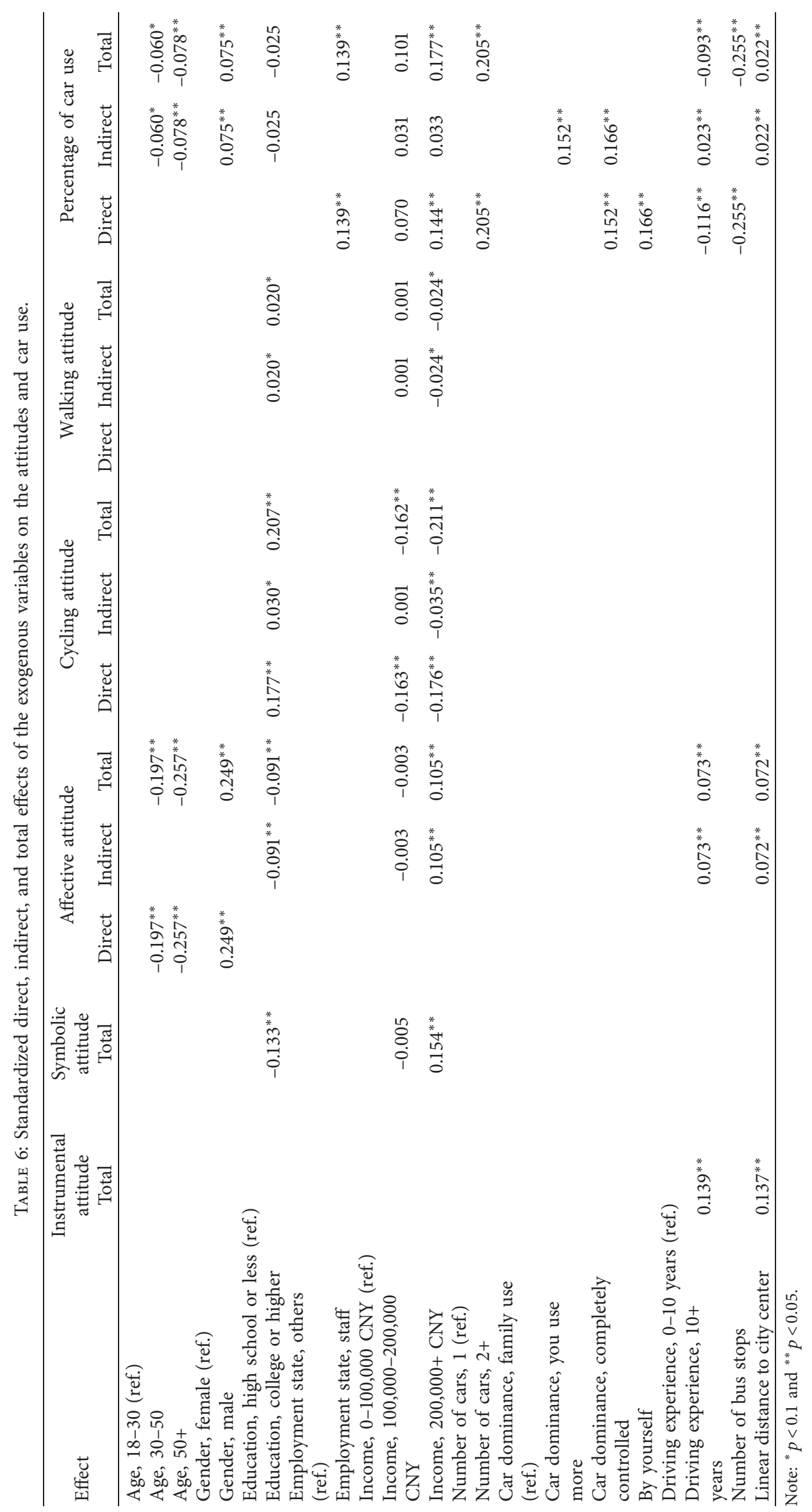




\section{Conclusion and Discussion}

This aim of this study is to explore the reasons why car use is attractive for short trips. Using the data collected from a travel survey conducted with car users in Kunming, the SEM is employed to explore the structural relationships between the car use for short trips, attitudes toward different travel modes, sociodemographics, and the built environment.

This study emphasizes the effects of the affective, instrumental, and symbolic attitudes toward cars on car use for short trips. The results indicate that the instrumental and symbolic attitudes toward cars have a significantly positive direct effect on affective attitude. This result is consistent with that of Lois and López-Sáez [24], which confirmed that drivers with high evaluation of the instrumental and symbolic effects of a car will increase their affection for their cars. The affective attitude has a significant positive direct and total effect on car use for short trips. Coincident with the finding of Steg [23], in our model, the instrumental attitude is not directly related to car use. The results reflect that compared with the instrumental function provided by cars, drivers' affection of cars seems to play a more important role in their car use for short trips.

It is noteworthy that although the symbolic attitude has a positive indirect effect on car use, the total effect is negative because the magnitude of the negative direct effect is relatively larger. To explain this result, we offer several possible reasons. First, the dominance of a car in a family is related to the individual car use. We compared the average scores of the symbolic attitude statements of the drivers who have different car dominances in their families. The average scores of the three categories are as follows: fully dominated by yourself (3.10), used more by yourself (3.05), and used more by your family members (3.35). This result shows that the drivers with more car dominance, which usually implies more car use, have a lower evaluation of the symbolic function. It may also indicate a psychological phenomenon that the more you lack something, the more you care about it. Second, the subjective biases of the respondents may also lead to this result. The average score of the symbolic attitude statements is the lowest among all the attitude statements. This may be the same situation as in the study by Steg et al. [22] in which when people were asked to evaluate the attractiveness of the aspects of car use, they deliberately avoided the symbolism of a car. We believe that the effect of the symbolic attitude on car use for short trips requires further verification and explanation by empirical and theoretical studies.

In agreement with Lois and López-Sáez [24], the affective attitude and car use are positively related to men and young drivers. Young drivers' higher evaluation of the affective effect of a car may lead their short trips use cars more. Education and the annual household income are also related to these attitudes, except the instrumental attitude. Concurrently, the number of bus stops around the residences has a negative effect on car use for short trips. These results confirm that people living in neighborhoods who are easily accessible by transit tend to reduce car use $[39,40]$. Moreover, as the distance to the city center increases, drivers will have a higher evaluation of the instrumental and affective attitudes toward a car and will use a car more for short trips. This result is similar to the previous study in China [41] that people being close to city center tend to reduce the car use. In addition, the employment status, driving experience, car dominance, and car ownership in a household have significant effects on car use for short trips.

Encouraging people to choose walk and cycle is one way to reduce unnecessary car use and improve individual health outcomes [42]. In this study, we also investigate the attitudes of car users toward walking and cycling, to gain a more comprehensive understanding of the views on the active modes of people who use cars in their daily lives. The results show significant negative effects of the symbolic attitude on the walking and cycling attitudes. Furthermore, the cycling attitude of drivers is negatively related to car use for short rips. However, the walking attitude has no significant effect on car use for short trips.

All of these findings may contribute to understanding car use behavior for short trips. Our research fills the gaps in the study of short car trips from a psychological perspective. Several implications for policymakers may be drawn from this study. Our results demonstrate the attitudes play an important role in car use for short trips. Greater attention should be given to psychological strategies to change the perceptions and attitudes toward cars. Furthermore, in order to promote a modal shift from short car trips to cycling, it may be worthwhile to make car users aware of the benefits of cycling through education and publicity. Our results demonstrate that the attitudes and car use for short trips are related to the sociodemographics of car users. Therefore, policies should be tailored toward specific targeted groups to make them more effective [23]. In addition, our results also claim that improving the accessibility of public transport can effectively reduce car use.

The current study also has several limitations. First, our data were based on the perception of the participants of their short trips. The difficulty of recalling past behaviors and their perceptions of travel information may have led to a certain bias. Second, this study only included a few built environment factors. Other factors such as the walking and cycling environment, neighborhood design, and land use are also essential factors influencing people to choose active modes [42]. In the future, we will consider more built environment factors to promote the shift of drivers from cars to active modes for short trips.

\section{Data Availability}

The data for this study was obtained through a shortdistance travel survey conducted in May 2019 in Kunming, Yunnan province, China. The data will be available to the scientific community by a data article, which will be submitted to an appropriate journal in the near future.

\section{Conflicts of Interest}

The authors declare no conflicts of interest. 


\section{Acknowledgments}

The authors thank all research assistants for data collection and processing. This research was funded by the National Natural Science Foundation of China (No. 71861017, No. $71661020)$ and the Talent Training Foundation of Yunnan Province, China (No. KKSY201702029).

\section{References}

[1] National Bureau of Statistics of China, China Statistical Yearbook, National Bureau of Statistics of China, Beijing, China, 2018.

[2] C. J. Bergstad, A. Gamble, O. Hagman, M. Polk, T. Gärling, and L. E. Olsson, "Affective-symbolic and instrumentalindependence psychological motives mediating effects of socio-demographic variables on daily car use," Journal of Transport Geography, vol. 19, no. 1, pp. 33-38, 2011.

[3] S. Paul, K. Born, K. Mcelduff et al., "Exploring the characteristics of short trips: implications for walk mode choice," in Proceedings of the Transportation Research Board 93rd Annual Meeting, Transportation Research Board, Washington, DC, USA, 2014.

[4] T. Sugiyama, D. Merom, H. P. van Der Ploeg, G. Corpuz, A. Bauman, and N. Owen, "Prolonged sitting in cars: prevalence, socio-demographic variations, and trends," Preventive Medicine, vol. 55, no. 4, pp. 315-318, 2012.

[5] L. Ming, S. Guohua, C. Ying et al., "Research on excessive short distance car trips in urban area," Journal of Beijing Jiaotong University, vol. 38, no. 3, pp. 15-21, 2014.

[6] C. Beckx, S. Broekx, B. Degraeuwe, B. Beusen, and L. Int Panis, "Limits to active transport substitution of short car trips," Transportation Research Part D: Transport and Environment, vol. 22, pp. 10-13, 2013.

[7] J. Lee, S. Y. He, and D. W. Sohn, "Potential of converting short car trips to active trips: the role of the built environment in tour-based travel," Journal of Transport \& Health, vol. 7, pp. 134-148, 2017.

[8] T. Jones, "Getting the British back on bicycles-the effects of urban traffic-free paths on everyday cycling," Transport Policy, vol. 20, pp. 138-149, 2012.

[9] T. Gehlert, C. Kramer, O. A. Nielsen, and B. Schlag, "Socioeconomic differences in public acceptability and car use adaptation towards urban road pricing," Transport Policy, vol. 18, no. 5, pp. 685-694, 2011.

[10] A. Carse, A. Goodman, R. L. Mackett, J. Panter, and D. Ogilvie, "The factors influencing car use in a cycle-friendly city: the case of Cambridge," Journal of Transport Geography, vol. 28, no. 100, pp. 67-74, 2013.

[11] L. Eriksson, J. Garvill, and A. M. Nordlund, "Interrupting habitual car use: the importance of car habit strength and moral motivation for personal car use reduction," Transportation Research Part F: Traffic Psychology and Behaviour, vol. 11, no. 1, pp. 10-23, 2008.

[12] H. T. Van, K. Choocharukul, and S. Fujii, "The effect of attitudes toward cars and public transportation on behavioral intention in commuting mode choice-A comparison across six Asian countries," Transportation Research Part A: Policy and Practice, vol. 69, pp. 36-44, 2014.

[13] A. Soltani, D. Pojani, S. Askari, and H. E. Masoumi, "Sociodemographic and built environment determinants of car use among older adults in Iran," Journal of Transport Geography, vol. 68, pp. 109-117, 2018.

[14] Y. Ding and H. Lu, "Activity participation as a mediating variable to analyze the effect of land use on travel behavior: a structural equation modeling approach," Journal of Transport Geography, vol. 52, pp. 23-28, 2016.

[15] G. Mattioli, J. Anable, and K. Vrotsou, "Car dependent practices: findings from a sequence pattern mining study of UK time use data," Transportation Research Part A: Policy and Practice, vol. 89, pp. 56-72, 2016.

[16] S. Cullinane and K. Cullinane, "Car dependence in a public transport dominated city: evidence from Hong Kong," Transportation Research Part D: Transport and Environment, vol. 8, no. 2, pp. 129-138, 2003.

[17] M. Verma, "Growing car ownership and dependence in India and its policy implications," Case Studies on Transport Policy, vol. 3, no. 3, pp. 304-310, 2015.

[18] D. Walton and S. Sunseri, "Factors influencing the decision to drive or walk short distances to public transport facilities," International Journal of Sustainable Transportation, vol. 4, no. 4, pp. 212-226, 2010.

[19] S. Kim and G. F. Ulfarsson, "Curbing automobile use for sustainable transportation: analysis of mode choice on short home-based trips," Transportation, vol. 35, no. 6, pp. 723-737, 2008.

[20] R. Cole, G. Turrell, M. J. Koohsari, N. Owen, and T. Sugiyama, "Prevalence and correlates of walkable short car trips: a crosssectional multilevel analysis," Journal of Transport \& Health, vol. 4, pp. 73-80, 2017.

[21] L. Steg and G. Tertoolen, "Affective motives for car use," in European Transport Conference: Transport, Planning, Policy and Practice, pp. 13-27, Cambridge, UK, 1999.

[22] L. Steg, C. Vlek, and G. Slotegraaf, "Instrumental-reasoned and symbolic-affective motives for using a motor car," Transportation Research Part F: Traffic Psychology and Behaviour, vol. 4, no. 3, pp. 151-169, 2001.

[23] L. Steg, "Car use: lust and must. Instrumental, symbolic and affective motives for car use," Transportation Research Part A: Policy and Practice, vol. 39, no. 2-3, pp. 147-162, 2005.

[24] D. Lois and M. López-Sáez, "The relationship between instrumental, symbolic and affective factors as predictors of car use: a structural equation modeling approach," Transportation Research Part A: Policy and Practice, vol. 43, no. 9-10, pp. 790-799, 2009.

[25] C. Bergstad, S. Fujii, and T. Gärling, "Effects of economic disincentives on private car use," Transportation, vol. 29, pp. 349-370, 2002.

[26] B. Gatersleben, Affective and Symbolic Aspects of Car Use, Elsevier, Amsterdam, Netherlands, 2007.

[27] A. De Nazelle, B. J. Morton, M. Jerrett, and D. CrawfordBrown, "Short trips: an opportunity for reducing mobilesource emissions?" Transportation Research Part D: Transport and Environment, vol. 15, no. 8, pp. 451-457, 2010.

[28] E. Maibach, L. Steg, and J. Anable, "Promoting physical activity and reducing climate change: opportunities to replace short car trips with active transportation," Preventive Medicine, vol. 49, no. 4, pp. 326-327, 2009.

[29] R. L. Mackett, "Why do people use their cars for short trips?" Transportation, vol. 30, no. 3, pp. 329-349, 2003.

[30] Kunming Traffic Transport Bureau, Data Report of Kunming Urban Residents Travel Survey, Kunming Traffic Transport Bureau, Kunming, China, 2016.

[31] A. M. El-Geneidy, P. R. Tétreault, and J. Surprenant-Legault, "Pedestrian access to transit: identifying redundancies and gaps using a variable service area analysis," in Proceedings of the Transportation Research Board 89th Annual Meeting, Transportation Research Board, Washington, DC, USA, 2009. 
[32] Z. Fang, C. Lee-Fang, L. Min-Tang et al., "Forecasting transit walk accessibility: regression model alternative to buffer method," Transportation Research Record, vol. 1835, no. 1, pp. 34-41, 2003.

[33] M. C. Rojas López and Y. D. Wong, "Attitudes towards active mobility in Singapore: a qualitative study," Case Studies on Transport Policy, vol. 5, no. 4, pp. 662-670, 2017.

[34] B. Gardner and C. Abraham, "Going green? Modeling the impact of environmental concerns and perceptions of transportation alternatives on decisions to drive," Journal of Applied Social Psychology, vol. 40, no. 4, pp. 831-849, 2010.

[35] M. J. Roorda and T. Ruiz, "Long- and short-term dynamics in activity scheduling: a structural equations approach," Transportation Research Part A: Policy and Practice, vol. 42, no. 3, pp. 545-562, 2008.

[36] P. T. Aditjandra, X. Cao, and C. Mulley, "Understanding neighbourhood design impact on travel behaviour: an application of structural equations model to a British metropolitan data," Transportation Research Part A: Policy and Practice, vol. 46, no. 1, pp. 22-32, 2012.

[37] T. F. Golob, "Structural equation modeling for travel behavior research," Transportation Research Part B: Methodological, vol. 37 , no. 1, pp. 1-25, 2003.

[38] C. A. Klöckner and T. Friedrichsmeier, "A multi-level approach to travel mode choice - how person characteristics and situation specific aspects determine car use in a student sample," Transportation Research Part F: Traffic Psychology and Behaviour, vol. 14, no. 4, pp. 261-277, 2011.

[39] V. Van Acker, P. L. Mokhtarian, and F. Witlox, "Car availability explained by the structural relationships between lifestyles, residential location, and underlying residential and travel attitudes," Transport Policy, vol. 35, pp. 88-99, 2014.

[40] L. Yu, B. Xie, and E. H. W. Chan, "Exploring impacts of the built environment on transit travel: distance, time and mode choice, for urban villages in Shenzhen, China," Transportation Research Part E: Logistics and Transportation Review, vol. 132, pp. 57-71, 2019.

[41] P. Næss, "Residential location, travel, and energy use in the Hangzhou metropolitan area," The Journal of Transport and Land Use, vol. 3, no. 3, pp. 27-59, 2010.

[42] S. Li, P. Zhao, H. Zhang, and J. Quan, "Walking behavior in the old downtown Beijing: the impact of perceptions and attitudes and social variations," Transport Policy, vol. 73, pp. 1-11, 2019. 